\title{
Ascites Drainage
}

National Cancer Institute

\section{Source}

National Cancer Institute. Ascites Drainage. NCI Thesaurus. Code C159342.

The systematic withdrawal of ascitic fluid from the abdominal cavity. 